R. G. Boothroyd, Int. J. of Safety and Security Eng., Vol. 7, No. 1 (2017) 19-30

\title{
THE IMPORTANCE OF PUBLIC PARTICIPATION IN MONITORING RISKS IN LARGE-SCALE INDUSTRIAL PROJECTS: AN AUSTRALIAN EXPERIENCE
}

\author{
ROCKLEY G. BOOTHROYD \\ Chartered Engineer, Queensland, Australia.
}

\begin{abstract}
This is a true report of the problems faced by a small, but reasonably affluent town in Australia, which had the misfortune to be built near a coal deposit. Although Australia has strict environmental laws, it is easy enough to circumvent them, sometimes with disastrous consequences. It took 6 years to demonstrate that the proposed introduction of underground coal gasification was so dangerous that it had to be banned. Devastation of the town was avoided by the efforts of a handful of 'concerned citizens'. This same group, now more experienced, was then able to assess the consequences of an open-cut mine as an alternative project. Apart from using the best knowledge available they were also able to develop new ideas beneficial to a wider society. One such example is detailed. This is the observation that coal miners in underground and open-cut mines tend to suffer from different coal-related illnesses. While trying to investigate this difference in physical/chemical terms, this research seemed to give an unclear explanation. This lends credence to the suspicion that stimulation of the human immune system may be a more plausible explanation. If this is true it is of much interest to medical science.

Keywords: open-cut coal mining, regulation and management, risk.
\end{abstract}

\section{INTRODUCTION}

Coal mining has moved significantly from using underground technology to open-cut methods. This is largely due to economic considerations but it also has the potential for better and safer working conditions for employed personnel.

There is a tendency in the open-cut industry to presume that these advantages also apply to the nearby resident population. However, this is not the case. In fact the very opposite is true. Open-cut coal mining is an unenclosed hazardous industry. The fact that it is unenclosed makes it very different from underground mining. For this reason it is dirtier and usually much more hazardous to nearby resident populations. Underground mining at least has the advantage that its emissions are contained and can be reduced by filtration or scrubbing measures.

\section{MINERAL RIGHTS IN AUSTRALIA}

With very few exceptions, the right to own freehold land in Australia is limited to the top-soil only. All mineral rights belong to the Crown, and in effect it is a source of income for the government in power. As is the case in other democracies, increasing public taxation revenue is unpopular at the ballot box. Consequently, the trend towards expensive American-style elections has made mineral development a high priority in government policy. In addition, large companies, using lobbyists, have been quick to establish advantageous relationships with governments by contributing to both political parties (see section 6).

\section{THE APPROVAL PROCESS FOR LARGE-SCALE INDUSTRIAL DEVELOPMENTS}

Australian rules for preservation of the environment are very strict. Nevertheless, these rules seem to be rendered less effective by the massive size of typical Environmental Impact 
Statements (EIS) and other documentation submitted by industrial developers. Typically, an EIS comprises about a dozen very expensively produced volumes, each about $10 \mathrm{~cm}$ thick. They are submitted for public comment in reference libraries for a period of time barely sufficient for any reader to peruse them. It is also difficult to evaluate them critically without considerable engineering experience. Moreover, this more careful scrutiny often finds that difficult areas in EIS documents are easily glossed over and concealed in what appears superficially to be a very impressive and comprehensive presentation.

The only reasonable conclusion is that 'lip service only' is being given to public scrutiny (see Section 6 for specific details). This is hardly unexpected: major corporations, from the leading organised religions downwards, usually do not like public interference in their affairs.

\section{EMISSION FACTORS}

To a large extent these EIS and other submissions have the convenience, as well as limitations of being desktop studies using established codes of practice such as emission factors [1-4]. Reliance is placed on the submitting company to devise and monitor their own project and report incidents, such as emission exceedance, to the Regulatory Authority. Fines for non-reporting can be applied by the Regulating Authority. Nevertheless, this form of non-resident regulating bureaucracy offers ideal opportunities for mistakes and misplaced information. In addition, this system of trust between a company and the Regulatory Authority has been found to be questionable in a commercially competitive world. Complaints from the local population are normally dealt with by the company. For the most part, the record of dealing with complaints has been found to be very inadequate [5]. Consequently, our local Kingaroy Concerned Citizens Group (KCCG, for details see Appendix I) has sought its own participation in the approval process of new projects. In addition, in view of the proximity of its population to the proposed industrial activity, it has requested a formal role in monitoring the safety of the project.

Emission factors $[1-4,6,7]$ are intended for general use but they are not beyond a number of criticisms. This is including comments [6] such as saying that emission factors can be 'site-specific' [8].

\subsection{The use and limitations of emission factors}

The physical mechanisms whereby engineering equipments produce emissions are usually exceedingly complicated. This is because numerous factors interact in a mathematically complicated and non-linear way. Consequently, it is near impossible, in nearly every case, to produce scientifically accurate mathematical expressions for emission rates.

For example, the dust raised in kilograms per year $\left(\mathrm{E}_{\mathrm{n}(\mathrm{kg} / \mathrm{yr})}\right)$ by a specified type $(\mathrm{n})$ of earth-moving equipment can be described by:

$$
\mathrm{E}_{\mathrm{n}(\mathrm{kg} / \mathrm{yr})}=\left[\mathrm{A}_{(\mathrm{t} / \mathrm{h})} \times \mathrm{OP}_{(\mathrm{h} / \mathrm{yr})}\right] \times \mathrm{EF}_{\mathrm{n}(\mathrm{kg} / \mathrm{t})}
$$

where the emission factor is $\mathrm{EF}_{\mathrm{n}(\mathrm{kg} / \mathrm{t})}$, which expresses the dust (or some other pollutant) emitted in kilograms for each tonne of machinery used. $\mathrm{A}_{(\mathrm{t} / \mathrm{h})}$ is the activity rate, which in this case is the weight in tonnes of machinery used in a typical hour of operation and $\mathrm{OP}_{(\mathrm{h} / \mathrm{yr})}$ is the number of hours per year that the machinery is used.

The first term in eqn (1) can be reduced by an additional multiplier, if a means is available to control the emission. If several methods of reducing emissions are used together, they themselves are multiplicative together to further reduce the estimated size of the emission. 
In addition, different expressions can be used for different categories of pollutants. For example, (nuisance only) dust would be for coarser ( $\geq$ PM 10) dust, whereas another similar eqn (1) would be used for the more dangerous respirable ( $\leq \mathrm{PM} 10)$ dust.

Mathematically empirical eqn (1) derives from:

$$
\mathrm{E}_{\mathrm{n}(\mathrm{kg} / \mathrm{yr})}=\varnothing\left(\mathrm{x}_{1}, \mathrm{x}_{2}, \mathrm{x}_{3}, \ldots \ldots . \mathrm{x}_{\mathrm{m}}\right)
$$

where $\mathrm{m}$ variables are involved usually in the emission of dust (or other pollutants). For dust, these factors include the weight of the vehicle; the number of wheels or tracks; the size of the wheels; types of tyres or tracks; how the vehicle is driven; factors related to the soil such as moisture content, the nature of the soil also involving its composition and particle size spectra, agglomeration forces between dust particles, climate, vegetative cover etc...All this illustrates the complexity involved [9].

In some more straightforward engineering situations, equations like eqn (2) can be rationalised into more easily used and accurate dimensionless numbers derived from dimensional analysis. Even, in more difficult cases, if the number of $\emptyset$-dependant variables is sufficiently small, partial modelling techniques can sometimes be used. When the number of relevant variables $\left(\mathrm{x}_{1}-\mathrm{x}_{\mathrm{m}}\right)$ is too large for these approaches, the statistical approach of emission factors must be used. This is an approach in which variables of lesser significance can be squeezed out of the final expression into a more important variable with which they interact. This third, and least satisfactory method [4], involves errors of uncertainty inherent in the use of statistical methods. Mostly, these errors are of two main types.

Firstly, some engineering systems may have been studied inadequately for developing empirical equations. Dust raised by blasting is one such example [10,11]. In passing it is worth a comment that the main purpose of blasting is comminution (reducing overburden and coal to a convenient size for handling by trucks and excavators). Industry has mostly been slow to modernise its techniques [11] such as exploiting nitrogen dioxide fume patterns to quantify the dispersal of respiratory dust. Even more useful than this is the use of drones for this purpose, developed by university researchers [10] and younger more entrepreneurial companies [12].

Secondly, other engineering systems may be well studied but equipments of different designs may be used in different projects. Usually these different designs have different performance details that affect the accuracy of the empirical equations used.

Leading authorities [2-4] that publish emission factors are somewhat coy about the statistical variation experienced when using their empirical (statistically based) equations. However, they classify the reliability of their equations into different groups. This is nevertheless only a qualitative approach. For reasons of user convenience and simplicity, they do not embark into a commentary about statistical variance of individual empirical equations but they do caution the user to always be careful. Thus, when using published emission factors, inevitably $50 \%$ of estimates is too high and 50\% is too low. The example in Appendix II may help to illustrate some of the problems and consequences of using emission factors in design.

\subsection{Are we still using archaic management systems in open-cut coal mines?}

The discussion in Sections 4, 4.1 is a microcosm of a system of management known as complexity analysis [9]. In complexity management the terms $\left(\mathrm{x}_{1}-\mathrm{x}_{\mathrm{m}}\right)$ in eqn (2) are independent variables called agents that tend to interact with each other in a non-linear way. They influence the function $\mathrm{E}_{\mathrm{n}(\mathrm{kg} / \mathrm{yr})}$ with a connectivity $(c)$. They also have different connectivities with 
each other as well as the dependant variable. This connectivity can be variable in the range $0 \leq \mathrm{c} \leq 1$. If $\mathrm{c}$ is small enough with respect to the $\mathrm{c}$ values of the other agents which are being considered, then this agent can be considered trivial and then ignored. Essentially this is also a method by which the simplified empirical emission factors can also be derived.

However, nobody is going to be interested in using complexity analysis to develop emission factors because these only apply to a small category of machines. Complexity management is a tool for managing large engineering systems with many independently operating engineering components. An open-cut coal mine is just such a system. However, there is one vital component missing in present day management of a coal mine. This is a control feedback system that can be used to optimise the performance of the mine. In complexity management this extra component has an effect that is known as 'self-organisation'. If data from continuous monitoring are used as this feedback system, then the complexity management tool can be used to enhance the functional efficiency of the mine continuously and at all times. This modern method is recommended.

\section{THE PROBLEM OF PROXIMITY TO SENSITIVE AREAS IN OPEN-CUT COAL MINES}

Three other acceptable methods of evaluating emissions are mentioned in the American emission factor user manual [2-4]. The first of these is the most accurate and reliable of all methods, namely to use direct and continuous monitoring. This method is considered an essential and vital incorporation when designing coal projects in sensitive areas. This applies even when emission factor predictions are also used in design.

\subsection{Epidemiological evidence for the health hazards in open-cut coal mining}

Open-cut coal mining is prevalent in Virginia, U.S.A., and numerous papers have reported the adverse health effects on residents nearby. Research carried out in Chinese coal fields [13-17] comes to similar conclusions. Coal miners in India are equally aware of these health problems [6-8]. Mostly, these papers [18-24] are well-researched scholarly works from prestigious universities and are published in peer-reviewed journals. They use statistical analysis to exclude other covariant effects on health such as smoking, obesity, drug-abuse, low income and poor education.

The evidence from this extensive literature is irrefutable and leads to the conclusion that long-term exposure to coal dust is injurious to human health. This evidence is not limited to lung, colorectal and skin cancers but also extends to kidney failure and cardiovascular disease and some other ailments also prevalent among heavy tobacco smokers. It is important to draw a distinction between occasional exposure to coal dust and the much more hazardous situation of continuous exposure. Because low levels of chemical contaminants have always existed, through evolution animals have adapted to occasional exposure by excreting these toxins. However, mammals have not adapted, and cannot adapt, except by massive mortality rates over aeons, to artificial and unnatural continuous exposure.

These overseas studies also reveal the increase in live birth defects from coal dust contamination $[25,26]$. This would be expected from the mutagenic effects of some of these polycyclic aromatic hydrocarbons (PAHs) in coal.

Popular publications such as [27] are easier to read and the maps of affected areas in this particular publication illustrate the magnitude of the problem. Nevertheless, a more critical reading of popular reports is required. For example, any suspicion that mountain top removal 
contributes significantly to the problem is open to question. The same pollution effects [28] are found in coal-mining areas in Illinois, which is very flat land.

Despite the extensive literature now available, it serves only to demonstrate the dangers in open-cut coal mining. Almost all of this literature concurs with the general opinion that more research is needed to understand the detailed mechanisms of damage to human health. This is a very complicated subject. As an illustration of this, despite the large amount of statistical data evaluated, much uncertainty still persists in the relative importance of silica and PAHs in the development of illness.

Much attention has been drawn to the aromatic nature of about 500 chemicals in coal. Many of these are PAHs. Most PAHs are harmless but about 15 are known strong carcinogens and a few others are sufficiently mutagenic to cause birth defects. PAHs exist naturally in the environment but at low concentrations. This is a hazard that most of us can tolerate. It is continuous exposure at larger concentrations that constitute the health risk. PAHs also occur in cigarette smoke, which has similar effects. The resulting illnesses from heavy tobacco smoking resemble those from inhaling coal dust. Smoking a single cigarette may seem harmless enough but we ban smoking in public places because of the incremental increase in hazard to community health. Logically, the same conditions should apply to emissions from open-cut coal mines in the vicinity of human settlements.

\section{TOWARDS A FAIRER DEVELOPMENT OF MAJOR INDUSTRIAL PROJECTS}

Local communities are always affected by local large-scale industrial projects. Both benefits and adverse consequences are inevitable. Consultation with the local community is specified as essential in the Terms of Reference of an EIS in Australia. However, the present system used for developing an EIS whereby it is developed privately and secretly by the company is most inadequate. This is because public scrutiny is confined to 40 days for perusing many volumes of a huge document that has been never seen before. This system has contributed to an attitude of widespread public mistrust by many other community groups.

It is suggested that an EIS should always be developed through regular meetings with the community. These meetings need to be formalised and recorded audio-visually so that there is no misunderstanding. Questions by all involved parties should always be 'on notice' in properly formulated agendas and minutes. The intention is to eliminate 'surprise' tactics and promote 'objectivity' in debate. This would require an adequate degree of understanding on the part of local community members who may wish to appoint experts for assistance.

KCCG is fortunate in that it can meet these needs from its own membership. For example, the KCCG management committee has at least three members with the competence to operate a certified dust sampler such as the Aeroqual Dust Sentinel [29]. In fact, they would also be able to operate the more advanced Dust Profiler [29] although this AU\$15,400 instrument is neither necessary nor suitable to merely confirm company dust measurements. Other less technically inclined members of KCCG could easily be trained to use the more simple handheld nephelometers. This activity is to supplement these confirmatory tests with regard to spatial and time-varying data. However, it seems that this proposition of using our members to check on company monitoring has fallen on deaf ears in the final terms of reference [30].

A comparison of the draft terms of reference (TOR) [31] the final TOR [30] and KCCG's review [32] of the draft TOR [31] confirms beyond any reasonable doubt that there was never any intention by the Regulatory Authority to recognise ref [32] seriously. For example, Section 5 in this article, which was included in [32] never got a mention. The same observation applies to anything else in [32]. Apart from a few minor corrections [30] and [31] are 
identical. Clearly, only 'lip service' is given to the concept of public rights, participation, contribution and commentary. Our Governments now have a well-developed system, to suit their own interests, of getting projects certified without interference, collecting Royalties and only making a check on performance if the developer ever reports a problem. They appear to have no intention of letting the public interfere with this cosy relationship. Our bad experience places doubt on the reliability of all previously approved projects.

This deplorable situation deserves, at least, some attempt at explanation. The malpractice [33-36] of political donations to both major parties by large corporations has not gone unnoticed by public pressure groups. These groups range from the relatively benign 'Lock the Gate' movement [37] to the much more assertive 'Get Up' organisation [38]. This public hostility towards large industrial corporations has induced an opposite reaction in the form of legislation that favours the rights of mineral developers. In fact, the legislation has gone so far as to deprive the public of some common law rights. Only recently has present legislation been revoked to allow landholders to challenge developers who deprive them of their underground water resources. Presumably our political masters realised that few of us have the resources to challenge major corporations in the courts. Nevertheless, exceptions can be made even with regard to public rights. It has been decided that no challenge can be made to the water demands of the massive and controversial Adani Carmichael coal mine.

Somehow we need to change this situation to one which is more cooperative rather than combative (see Section 9).

\section{EXTENDING PUBLIC PARTICIPATION TO LOCALITIES WITH LIMITED HUMAN RESOURCES}

With regard to Section 6 it could be argued that not all local communities are as fortunate as KCCG. When UCG initially came to public attention, KCCG was brought into existence by two badly affected residents. One was an agricultural scientist and the other a secondary school teacher, who also has a remarkable panache for public relations work. They were soon joined by another and very welcome secondary school science teacher. Much later the present author joined the group together with others who contributed more expertise.

It is local councils which often bear the brunt of large developments in their vicinity. Problems with water supply are a common concern. It seems logical that a suitably qualified council official could be given the task of forming a suitable public participation group. Local retired residents with appropriate experience can probably be lured from comfortable retirement with a promise of a $5 \%-10 \%$ discount on their council rates. Younger experts can also be attracted likewise to an organisation that can also become a good social club in its own right. It is often surprising how much latent local talent exists in small communities.

\section{POLITICAL ADVANTAGES OF GREATER PUBLIC PARTICIPATION IN MAJOR INDUSTRIAL DEVELOPMENTS}

There is some evidence to suggest that our present democratic processes are under threat internationally. Examples are the British 'Brexit' departure from full unity with the European Community; the surprising election of Donald Trump as the next United States President and the recent tendency to 'hung-parliaments' in Australia because 25\% of the electorate no longer give first preference votes to the two main political parties. These observations seem to point to a suspected growing dissatisfaction with the democratic system. Perhaps it could be argued that our parlimentarians are developing a warped view of the real meaning of 
democracy? Is it enough to pass an act of parliament with a slim $1 \%$ majority? Some other lesser organisations require more than a $1 \%$ majority in their constitution. Democratic enforcement of a contentious issue to the detriment of a minority group can easily become a pernicious form of tyranny. Only with respect for the reasonable rights of minority groups can the democratic process be considered a reasonable one. The right to object should also include the right to a reasoned reply to an objection. The suggestions in this article for using more public participation in major developments is consistent with such viewpoints.

Another advantageous aspect of enhanced public participation is that it improves the guiding principle of the separation of powers. The three components in a democracy of the separation of powers are the Judiciary, the Legislature, and Enforcement. Enforcement is the administrative arm which includes policing and regulating. The weakness in modern parliamentary democracy is that the Legislature and Enforcement arms have tended to become linked together within the parliament. Ill-considered 'fait accompli' directives from Parliament such as the costly Linc Energy debacle described in Appendix I are likely to result when there is an inadequate separation of powers. Members of the public, who support a civilised society, have always been a necessary part of law and regulation enforcement and this implies the justification of significant public participation.

\section{CONCLUSIONS}

The system of organisation, management and control of major mining projects in Australia is seriously flawed. It is intended to take remedial action. The proposer of this project plans to complete certain related administrative tasks by March 2017 and then appoint their project manager. Thereafter it will take at least 12 months to complete their EIS, so project approval can be expected by about mid-year 2018. Up to this time KCCG expects to be heavily involved with the project, attempting to incorporate the improvements discussed in this article. Further up-to-date details can be obtained from KCCG's spokesperson, John Dalton (email address given in ref. [32]).

Large corporations have adapted to a changing world more competently than most of the rest of us. The corporations display superior strategy when it comes to paying tax; fulfiling contracts and even avoiding rehabilitation [37]. Global Corporations also seem to recognise their own fundamental weakness in a democracy. Perhaps this may explain why they seem to be trying so hard to establish control for their own benefit and security. Maximising their influence in public media seems to be one such example. Global corporations are nevertheless a vitally important part of society because of their unique contributions to society. They also have a right to protection but the correct balance between public and corporate interests seems to have been lost to us by using a very competitive approach.

Overseas experience with illness from continuous exposure to coal dust implies the need for continuous monitoring of these emissions when in close proximity to human settlements. It is recommended that this safety measure is best checked by involved individuals who may be affected. This has been found to be feasible. Reliable data are always necessary in the event of a future damages claim.

Although global warming from GHG may cause coal mining to be a declining industry worldwide, we will still need the best mining technology such as that obtainable from complexity management, which needs continuous monitoring for it to work at all. For example, the era of molten salt nuclear reactors [39] has hardly started yet and we will need the best practice to mine thorium and process it. In no way can we describe mining itself as a declining industry. 
Admittedly, all these problem areas are only a part of a much larger socio-economic problem as Australia struggles to adapt to a more fiercely competitive global world. The need to regain a more balanced economy in Australia is also a vital ingredient in solving our problems. As automated mechanisation supplants the value and use of human labour, our own problem, which is largely with unemployment and income inequality is also fast becoming a very serious world-wide issue as other nations come under the same influence.

\section{APPENDIX I: A BRIEF HISTORY OF THE KINGAROY CONCERNED CITIZENS GROUP (KCCG)}

This organisation came into being in 2008 and the present author joined the organisation later. KCCG has a management group of about 10 people and a membership of about 200. It enjoys good support from the majority of people in the vicinity of Kingaroy. Over the years, the group has made a number of technical contributions not only for underground coal gasification but also for related coal industries such as coal seam gas and water management. On March $1^{\text {st }}, 2010$, the present author asked our local member to table a report in the Queensland Parliament advising against the use of UCG as it was a 'cheap and nasty' technology with a deplorable history going back some 100 years. This report and related documentation are now on open access for anyone to read. However, this submission was too late as 3 UCG trials had already been authorised in the usual fait accompli confidential manner of conducting Queensland Government business.

Fortunately for Kingaroy, after only burning $40 \mathrm{~m}^{3}$ of coal, an underground explosion blew some of the pipework out of the ground and benzene and toluene contaminated groundwater. This trial was terminated even though the contamination was very small. The other two trials were allowed to continue. An independent committee of three eminent Queensland University professors were appointed to give advice on UCG matters. These professors, specialists in other fields, did remark on the steep learning curve experienced. They did eventually advise against the technology, which has now been banned. The most promising trial (Linc Energy) has more recently contaminated land which is expected to cost \$29 million in damages. This is sub-judice and before the courts so no further comments are possible.

\section{APPENDIX II: DESIGN EXAMPLE USING EMISSION FACTORS}

N. B. This data report [40], from one of the better engineering consulting companies, cannot be claimed to have official status as it has not yet been countersigned by a senior consultant engineer. Nevertheless, the predicted data serve to illustrate the points raised. The estimated emission values in Table 1 have also been rounded off to 2-3 significant figures. The manual used was an earlier 2001 version but it is almost identical to the 2012 version [1].

The only emission control factor used in the estimates was $75 \%$ for the largest dust contributor (124 tonnes/year for PM2.5 dust raised by heavy machinery on unpaved roads). This requires 2 litres $/ \mathrm{m}^{2}$ per hour of water to lay the dust. This uncertain factor and the variable influence of climate and variable operator conduct makes this estimate one of the more uncertain values in the data shown in Table 1. Yet, the dust raised from unpaved roads is the most important contributor to emissions. The sensitivity of the Kingaroy proposal is about 12 times larger than the sensitivity of the Colton project yet the projects are similar, broadly speaking. Although challenged in the Land Court recently, judgement was held in favour of Colton's proposer. The much higher sensitivity of the Kingaroy proposal supports the view that direct monitoring is vitally necessary in the Kingaroy project. 
Table 1: Summary of dust emissions from the Colton mine [40].

\begin{tabular}{llll}
\hline Activity & $\begin{array}{l}\text { TSP emissions } \\
\text { (Tonnes/yr) }\end{array}$ & $\begin{array}{l}\text { PM10 emissions } \\
\text { (Tonnes/yr) }\end{array}$ & $\begin{array}{l}\text { PM2.5 emissions } \\
\text { (Tonnes/yr) }\end{array}$ \\
\hline Wheel dust unpaved roads & 3940 & 1236 & 124 \\
Bulldozing coal & 599 & 173 & 21 \\
blasting & 264 & 137 & 8 \\
Bulldozing overburden & 47 & 9 & 5 \\
drilling & 42 & 22 & 1.3 \\
Loading/unloading trucks with & 77 & 36 & 9 \\
overburden & & & \\
Loading/unloading coal & 36 & 2.9 & 2.2 \\
Wind erosion from stockpiles & 37 & 19 & 0.9 \\
Other smaller items & 7 & 3 & 0.4 \\
\hline
\end{tabular}

There is no code available to measure directly the sensitivity of a mine near a population centre. This value for sensitivity depends on how it is calculated. Comparison was made with the more sheltered Colton mine operating at maximum capacity of $18 \mathrm{Mt} / \mathrm{yr}$, whereas the value is $7 \mathrm{Mt} / \mathrm{yr}$ at Kingaroy [41]. The much higher sensitivity value for Kingaroy is considered sufficient to justify continuous monitoring of harmful effects.

\section{APPENDIX III: CAN WE FIND A CURE FOR LUNG CANCER USING OUR OWN IMMUNE SYSTEM?}

It has long been known [42] that underground coal miners are less prone to lung cancer than the general population. These surprising statistics have been corrected for age and smoking. Yet, coal miners are more prone to other forms of coal-caused lung disease such as pneumoconiosis (black lung disease) involving tissue scarring (pulmonary fibrosis), inflammation and accumulation of macrophage cells in the lower lung found to be charged with an excess of coal dust particles which the macrophages are attempting to destroy. This curious statistical fact remains mysterious to this day and is of sufficient interest for inclusion in a more recent medical journal editorial [42].

An attempt was made to explain the above observations in physical instead of chemical terms. Underground coal workers normally operate machinery with their backs to ventilation air. Consequentially the especially fine (e.g. PM2.5) dust is swept away from the operator but the larger particles are more easily inhaled. These larger particles would tend to lodge in the upper part of the respiratory tract and not pass deep into the lower lung and could possibly stimulate an immune response that might account for the strange statistics relating to lung cancers. There is a huge amount of published data on the health of coal miners. Most of this relates to impaired health of living miners measured by spirometers but not much seems to come from post-mortem analysis that might clarify the above suggestion. Results are therefore inconclusive suggesting that a chemically related explanation [43] may be a more convincing alternative theory.

This earlier study [43] suggested that a reduction of metabolisation of inspired PAHs changing into noted carcinogens such as benzo[a]pyrene may be an explanation for the strange reason why underground coal miners often avoid lung cancer. 
Clearly, any further study is well beyond the capabilities of KCCG. These notes are added here only because the future treatment of lung cancer with an immunological approach is a very attractive proposition. Lung cancers are among the most deadly forms of cancer in human experience and an improved method of treatment is needed.

CSG: $\quad$ Coal seam gas

EIS: $\quad$ Environmental Impact Statement

KCCG: Kingaroy Concerned Citizens Group

TOR: $\quad$ Terms of reference (for an EIS)

TSP: Total solids present in a dust sample

UCG: Underground coal gasification

\section{REFERENCES}

[1] Anon. National pollutant inventory: emission estimation technique manual for mining (version 3.1) Department of sustainability, environment, water, population and communities, Australian Government, January, 2012.

[2] Anon, Compilation of air pollutant emission factors, AP-42, fourth edition United States Environmental Protection Agency. Office of air and radiation, Office of air quality planning and standards, Research Triangle park, North Carolina, 27711, 1985.

[3] Anon, Compilation of air pollutant emission factors, AP-42, fourth edition United States Environmental Protection Agency. Office of air and radiation, Office of air quality planning and standards, Research Triangle park, North Carolina, 27711, 1998.

[4] http://www.epa.gov/ttnchie1/AP-42.html

[5] Cleary, P., Living in the dusty shadow of coal mining. The Australian Newspaper, January 28, 2012.

[6] Roy, S., Adhikari, G.J. \& Singh, T.N., Development of emission factors for quantification of blasting dust at surface coal mines. Journal of Environmental Protection, 1, pp. 346-361, 2010. https://doi.org/10.4236/jep.2010.14041

[7] Abdollahisharif, J., Bakhtavar, E. \& Nourizadeh, H., Monitoring and assessment of pollutants resulting from bench-blasting operations. Journal of Mining \& Environment, 7(1), pp. 109-118, 2016.

[8] Pandey, B., Agrawal, M. \& Singh, S., Assessment of air pollution around coal mining areas: emphasising on spatial distribution, seasonal variations and heavy metals, using cluster and principal component analysis. Atmospheric Pollution Research, 5, pp. 79-86, 2014. https://doi.org/10.5094/APR.2014.010

[9] Rzevski, G. \& Skobelov, P., Managing Complexity. Wit press: Southampton \& Boston, pp. 1-198, 2014.

[10] Alvarado, M., Gonzalez, F., Fletcher, A. \& Doshi, A., Towards the development of a low cost airborne sensing system to monitor dust particles after blasting at open pit coal mines. Sensors, 15(8), pp. 19667-19687, 2015. https://doi.org/10.3390/s150819667

[11] Goswani, T. \& Brent, G.I., A new mining method -orica mining services, available at http:// www.oricaminingservices.com/.../Coal/...Minimise\%20coal\%20Loss/.../1.2Str... 
[12] Fenigson, E., Automated drones-a giant step in the mining value chain, a white paper, efratf@aerobotics.co.il, 2016.

[13] Wang, X.W., Zhong, N.N., Hu, D.M., Liu, Z.Z. \& Zhang, Z.H., Polycyclic aromatic hydrocarbon (PAHs) pollutants in groundwater from coal gangue stack area: characteristics and origin. Water Science and Technology, 59(5), pp. 1043-1051, 2009. https://doi.org/10.2166/wst.2009.050

[14] Zhao, L., Hou, H., Shangguan, Y., Cheng, B., Xu, Y., Zhao, R., Zhang, Hua, X. \& Zhao, $\mathrm{X}$., Occurrence, sources and potential human health risks of polycyclic aromatic hydrocarbons in agricultural soils of the coal production area surrounding Xinzhou, China. Ecotoxicology and Environmental Safety, 108, pp. 120-128, 2014. https://doi.org/10.1016/j.ecoenv.2014.05.034

[15] Li, Y., Zhang, L., Hou, W. \& Li, I.N., Research on content, distribution and health risk assessment of PAHs in surface dust in Shenyang City. Nature Environment \& Pollution Technology, 14(3), p. 721, 2015.

[16] Kim, K-H., Jahan, S.A., Kabir, E. \& Brown, R.J.C., A review of airborne polycyclic aromatic hydrocarbons (PAHs) and their human health effects. Environment International, 60, pp. 71-80, 2013.

https://doi.org/10.1016/j.envint.2013.07.019

[17] Zhou, B. \& Zhao, B., Population inhalation exposure to polycyclic aromatic hydrocarbons and associated lung cancer risk in Beijing region: Contributions of indoor and outdoor sources and exposures. Atmospheric Environment, 62, pp. 472-480, 2012. https://doi.org/10.1016/j.atmosenv.2012.08.059

[18] Hendryx, M., Leah, W., Juhua, L. \& Bo, W., Self-reported cancer rates in two rural areas of west Virginia with and without mountaintop coal mining. Journal of Community Health, 37(2), pp. 320-327, 2012.

https://doi.org/10.1007/s10900-011-9448-5

[19] Hendryx, M., Mortality from heart, respiratory, and kidney disease in coal mining areas of Appalachia. International Archives of Occupational Environmental Health, 82(2), pp. 243-249, 2009.

https://doi.org/10.1007/s00420-008-0328-y

[20] Hendryx, M., Mortality in appalachian coal mining regions: the value of statistical life lost. Public Health Reports, 124, pp. 541-550, 2009.

[21] Hendryx, M. \& Ahern, M.A., Relations between health indicators and residential proximity to coal mining in west Virginia. American Journal Of Public Health, 98(4), pp. 669-671, 2008.

https://doi.org/10.2105/AJPH.2007.113472

[22] Hendryx, M., O’Donnell, K. \& Horn, K., Lung cancer mortality is elevated in coal mining areas of Appalachia. Lung Cancer, 62(1), pp. 1-7, 2008.

https://doi.org/10.1016/j.lungcan.2008.02.004

[23] Jenkins, W.D., Christian, W.J., Mueller, G. \& Robbins, K.T., Population cancer risks associated with coal mining: a systematic review. PLos One, 8(8), e71312, 2013. https://doi.org/10.1371/journal.pone.0071312

[24] Aneja, V.P., Isherwood, A. \& Morgan, P., Characterization of particulate matter (PM10) related to surface coal mining operations in Appalachia. Atmospheric Environment, 54, pp. 496-501, 2012.

https://doi.org/10.1016/j.atmosenv.2012.02.063 
[25] Ahern, M., Mullett, M., Mackay, K. \& Hamilton, C., Residence in coal-mining areas and low birth weight outcomes. Maternal Child Health, 15(7) pp. 974-979, 2011. https://doi.org/10.1007/s10995-009-0555-1

[26] Ahern, M.M., Hendryx, M., Conley, J., Fedorko, E., Ducatman, A. \& Zullig, K.J., The association between mountaintop mining and birth defects among live births in central Appalachia, 1996-2003. Environmental Research, 111(6), pp. 838-846, 2011. https://doi.org/10.1016/j.envres.2011.05.019

[27] Appalacian Voices-Human health impacts, available at http://appvoices.org/end-mountaintop-removal/health -impacts/.

[28] Mueller, G.S., Clayton, A.L., Zahnd, W.E., Hollenbeck, K.M., Barrow, M.E., Jenkins, W.D. \& Ruez, D.R., Geospatial analysis of cancer risk and residential proximity to coal mines in Illinois. Ecotoxicology and Environmental Safety, 120, pp. 155-162, 2015. https://doi.org/10.1016/j.ecoenv.2015.05.037

[29] http://www.aeroqual.com

[30] Anon, Terms of reference for an environmental impact statement, South Burnett Coal Project, available at www.statedevelopment.qld.gov.au, December 2016.

[31] Anon, Draft terms of reference for an environmental impact statement. South Burnett Coal Project, available at www.statedevelopment.qld.gov.au, October 2016.

[32] KCCG, Public comments and response re. EIS draft terms of reference, South Burnett Coal Project, request free copy from jdalton59@gmail.com November, p. 1272016.

[33] Anon, The companies paying more in political handouts than tax, 26 November, 2016. info@getup.org.au

[34] Edwards, B.M., Dark money: the hidden millions corrupting Australian politics, a special report commissioned by the get up organisation, 16 pp., University of New South Wales, available from info@getup.org.au 2016.

[35] Hutcheons, G., Australia's political donations: $85 \%$ of privately raised funds 'not declared' The Guardian Newspaper, 15 November, 2016.

[36] Harris, R., Research sheds light on dark money in politics, Herald Sun Newspaper, November 16, 2016, available at www.heraldsun.com.au

[37] Hutton, D., They're trying to cut and run (Blair Athol mine to be sold for $\$ 1$ to avoid rehabilitation), info@lockthegate.org.au pp. 1-3, 14 December, 2016.

[38] info@getup.com.au

[39] Boothroyd, R.G., Integrated molten-salt nuclear reactor systems for base-load power plants. International Journal of Energy Production and Management, 2(1), pp. 19-51, 2017. https://doi.org/10.2495/EQ-V2-N1-39-51

[40] ASX Consulting Engineers Pty Ltd, Colton mine Project, Appendix J, Air quality impact and greenhouse gas assessment, pp. 1-44, 16/08/2011, available at http://newhopegroup.com.au/content/projects/development/colton

[41] Moreton Resources, ASX Announcement, South Burnett coal project pre-feasibility result pp. 1-37, 21 December, 2015. Available at www.moretonresources.com.au 2.

[42] Stayner, L.T. \& Graber, J.M., Does exposure to coal dust prevent or cause cancer? Occupational Environmental Medicine, 68, pp. 167-168, 2011. https://doi.org/10.1136/oem.2009.048223

[43] Ghanem, M.M., Porter, D., Battelli, L.A., Valyathan, V., Kashon, M.I., Ma, J.Y., Barger, N.W., Nath, J., Castranova, V. \& Hubbs, A.F., Respirable coal dust particles modify cytochrome P4501A1 (CYP1A1) expression in rat alveolar cells. American Journal of Respiratory Cell and Molecular Biology, 31, pp. 171-183, 2004.

https://doi.org/10.1165/rcmb.2003-0425OC 